\title{
Utilisation des pommes de terre par les vaches laitières
}

\author{
F Morel d'Arleux 1, M Maréchal 2, R Samson 3, A de Montigny 4, \\ JM Lebrun ${ }^{5}$, F Ratier 6 \\ 'Institut de l'Elevage, Comité National des Co-produits, 75595 Paris Cedex 12 ; 2Lycée de Radinghem, \\ 62310 Fruges ; ${ }^{3}$ Lycée de Merval, 76220 Bremontier-Merval; ${ }^{4}$ Comité National Interprofessionnel \\ de la Pomme de Terre, 75008 Paris ; ${ }^{5}$ Chambre d'Agriculture, 62051 St-Laurent-Blanzy ; \\ ${ }^{6}$ Chambre d'Agriculture, 76230 Bois-Guillaume Cedex, France
}

Les écarts de triage et les excédents de pommes de terre sont disponibles depuis plusieurs années pour l'alimentation des animaux. Leur utilisation dans des rations à base d'ensilage de maïs permet-elle de réduire l'écart entre le taux butyreux et le taux protéique, et le coût de la ration?

Quatre essais ont été réalisés avec des vaches Holstein (essais 1 et 3 ) ou Normandes (essais 2 et 4 ) en phase descendante de lactation, et recevant (lot P) ou non (lot T) des pommes de terre entières et crues à raison de 3,1 à $4,3 \mathrm{~kg} \mathrm{MS} / \mathrm{j}$. Les pommes de terre étaient offertes en deux repas par jour, en remplacement du fourrage (ensilage de maïs, essais 1 et 2) ou des céréales du concentré (essais 3 et 4 ). Selon les essais, les lots étaient constitués de 12 à 14 vaches et les périodes expérimentales ont duré de 12 à 14 semaines.
L'apport de pommes de terre a modifié l'ingestion totale $+1,8 \mathrm{~kg}$ de MS (essais 1 et 2), $+0,8 \mathrm{~kg}$ (essai 3 ), $+0,1 \mathrm{~kg}$ (essai 1). Cet effet favorable avait été montré par de Brabander et al (1982-1993, Revue Agriculture, Vol 35, 3269-3291 et Vol 44).

L'ingestion des pommes de terre a entraîné une production de lait brut plus faible : $-2,6 \mathrm{~kg}$, $+0,1 \mathrm{~kg},-1,1 \mathrm{~kg},-0,7 \mathrm{~kg}$ et les taux ont été améliorés: TB $+3,9 \mathrm{~g} / \mathrm{kg},+1,9,+1,4,0$; TP $+3,7,+1,5,+1,4,+1,3$ respectivement pour les essais $1,2,3$ et 4 .

Ces quatre essais ont bien montré que les pommes de terre peuvent être incorporées en quantités importantes dans la ration jusqu'à $4 \mathrm{~kg}$ de MS/vache/jour sans problèmes sanitaires particuliers. La valorisation des pommes de terre n'est correcte que si leur apport permet de réduire d'autant les quantités de concentré distribuées.

\begin{tabular}{|c|c|c|c|c|c|c|c|c|}
\hline \multirow[t]{2}{*}{ Régime } & \multicolumn{2}{|c|}{ Essai 1} & \multicolumn{2}{|c|}{ Essai 2} & \multicolumn{2}{|c|}{ Essai 3} & \multicolumn{2}{|c|}{ Essai 4} \\
\hline & $\mathrm{T}$ & $\mathrm{P}$ & $T$ & $\mathrm{P}$ & $\mathrm{T}$ & $P$ & $\mathrm{~T}$ & $P$ \\
\hline \multicolumn{9}{|c|}{ Consommation (kg de MS/NL/j) } \\
\hline Ensilage-maïs & 13,9 & 12,4 & 13,9 & 11,8 & 16,4 & 15,4 & 14,5 & 14,1 \\
\hline Pommes de terre & - & 4,3 & - & 4,0 & 0,2 & 3,5 & - & 3,1 \\
\hline Concentré & 5,9 & 4,9 & 3,4 & 3,3 & 6,0 & 4,5 & 4,5 & 1,9 \\
\hline Total & 19,8 & 21,6 & 17,3 & 19,1 & 22,6 & 23,4 & 19,0 & 19,1 \\
\hline Lait $(\mathrm{kg} / \mathrm{j})$ & 28,7 & $26,1^{*}$ & 20,4 & 20,5 & 29,9 & 28,8 & 19,0 & 18,3 \\
\hline Taux butyreux (g/kg) & 41,0 & 44,9 & 44,0 & $45,9^{\star}$ & 42,1 & 43,5 & 44,6 & 44,6 \\
\hline Taux protéique $(\mathrm{g} / \mathrm{kg})$ & 31,1 & $34,8^{\star}$ & 33,6 & $35,1^{*}$ & 30,5 & 31,9 & 34,8 & 36,1 \\
\hline
\end{tabular}

* Différence entre $T$ et $P$ significative au seuil de $5 \%$ 